\title{
Concomitant HIV infection in newly diagnosed multiple myeloma patients is hard to recognise and should be tested for routinely in areas of high endemicity
}

\author{
J J B de Groot, ${ }^{1,2}$ MSc; M J Webb, ${ }^{2} \mathrm{MB}$ ChB, MMed; J E Raubenheimer, ${ }^{3} \mathrm{PhD}$; M C Struwig, ${ }^{4} \mathrm{MMedSc}, \mathrm{PhD}$; \\ V J Louw, ${ }^{2} \mathrm{MB} \mathrm{ChB}, \mathrm{MMed}, \mathrm{FCP}(\mathrm{SA}), \mathrm{PhD}$ \\ ${ }^{1}$ Department of Haematology, VU University Medical Center, Amsterdam, The Netherlands \\ ${ }^{2}$ Division of Clinical Haematology, Department of Internal Medicine, Faculty of Health Sciences, University of the Free State, Bloemfontein, South Africa \\ ${ }^{3}$ Department of Biostatistics, Faculty of Health Sciences, University of the Free State, Bloemfontein, South Africa \\ ${ }^{4}$ Office of the Dean, Faculty of Health Sciences, University of the Free State, Bloemfontein, South Africa
}

Corresponding author: J J B de Groot (jjbdegroot@gmail.com)

\begin{abstract}
Background. Over the past three decades much has changed in the treatment and outcomes of patients suffering concurrently from both multiple myeloma (MM) and HIV. While the prevalence of MM appears to be higher in HIV-positive individuals than in those who are uninfected, early recognition of patients suffering from both diseases is difficult and little information is available on their demographics and clinical presentation.

Objective. To compare the presenting features of HIV-positive patients diagnosed with MM with those of HIV-negative patients.

Methods. A single-centre, retrospective cohort study included 16 HIV-positive and 73 HIV-negative patients diagnosed with MM, in order to compare variables related to the clinical presentation of both conditions.

Results. HIV-positive patients presented with MM at a significantly younger age, and had fewer osteolytic lesions, less renal impairment and lower neutrophil counts. Disease stage, gender, pathological fractures, bone marrow plasmacytosis, plasmacytomas and lymphocyte counts were comparable, emphasising the difficulty of identifying these patients. The HIV-positive patients had relatively high CD4 counts and a low prevalence of abnormal Freelite kappa/lambda ratios. All HIV-positive patients presented with paraproteins of the immunoglobulin G (IgG) type, implying a possible relationship between MM and an IgG response to HIV antigens.

Conclusions. On the basis of our findings and literature on the treatment of both diseases, we suggest that HIV be tested for routinely in younger MM patients, especially in areas with a high prevalence of HIV. The integration of our results into the sparse knowledge on the role of HIV infection-related MM provides possible new insights into the interaction between these diseases.
\end{abstract}

S Afr Med J 2017;107(9):781-787. DOI:10.7196/SAMJ.2017.v107i9.12360

Multiple myeloma (MM) accounts for $1 \%$ of all malignancies, $10 \%$ of all haematological malignancies in whites and $20 \%$ in African Americans. ${ }^{[1]}$ Two meta-analyses covering the USA, Australia, Italy, Switzerland and the UK showed an increased incidence of MM in HIV-positive patients, with a standardised incidence rate of 2.71 (95\% confidence interval (CI) 2.13 - 3.44) and a relative risk (RR) of $1.9-6.5 .^{[2,3]}$ This differs from the relative risk in South African (SA) studies, in which an RR of $0.7-0.9$ was described, ${ }^{[4,5]}$ which could be attributed to under-reporting and earlier death from other AIDSrelated illnesses.

The pathogenic mechanisms associated with the proposed increased frequency of MM in HIV patients compared with the general population are not well understood, and several possibilities have been reviewed. ${ }^{[6]}$ Although HIV probably does not play a direct role in the pathogenesis of MM, as it can neither infect B-cells or plasma cells nor drive their malignant transformation, several indirect mechanisms may be involved in the pathogenesis of plasmacell neoplasias in HIV-associated cases. ${ }^{[7]}$

Polyclonal hypergammaglobulinaemia resulting from chronic B-cell stimulation and loss of normal T-cell function, as seen in the setting of HIV infection, could result in an inclination towards the development of MM in genetically predisposed individuals. Also, several case reports have been presented in which the monoclonal antibody was shown to react with HIV-specific antigens, suggesting that HIV antigens may act as super-antigens and directly stimulate the proliferation of malignant plasma cells..$^{[8-11]}$ Furthermore, immunodeficiency caused by HIV-induced T-cell depletion was found to increase the risk of developing several types of cancer, including $\mathrm{MM}^{\left[{ }^{[3]}\right.}$

Over the past three decades, much has changed in the treatment and outcomes of patients suffering from both MM and HIV. Until recently, only case reports had been published, mostly on HIV-positive MM patients with unusual clinical presentations and aggressive clinical courses. ${ }^{[12-15]}$ Many of these studies highlight the difficulties in diagnosis of MM in HIV-positive patients, as the two diseases share some common clinical features, especially anaemia, fatigue, weight loss, bone marrow plasmacytosis, renal insufficiency and recurrent bacterial infections. In 2014, Li et al. ${ }^{[16]}$ published a retrospective analysis of 10 symptomatic HIV-positive MM patients treated for both conditions. They found that HIV-positive patients on highly active antiretroviral therapy had significantly superior overall survival and progression-free survival compared with their HIVnegative counterparts, making early recognition of patients suffering from both diseases even more necessary. In contrast to what might be suspected from cases described previously, no significant differences were found in the characteristics of the HIV-positive patients 
compared with their HIV-negative counterparts, with age, gender, renal function, bone lesions and stage of disease all being similar. ${ }^{[16]}$

Other recently published case reports and single-centre experiences have shown similar favourable responses and increased survival in HIV-positive MM patients treated with either thalidomide-based chemotherapy or myeloablative chemotherapy and autologous stemcell transplantation. ${ }^{[16-20]}$ In a phase I study, the HIV protease inhibitor nelfinavir was considered safe and showed promising activity in patients with advanced bortezomib-refractory MM by triggering the unfolded protein response and thereby overcoming the biological features of proteasome inhibitor resistance in these patients. ${ }^{[21]}$

\section{Objective}

To investigate the presenting features of HIV-positive patients newly diagnosed with MM. These patients were compared with HIVnegative MM patients from the same population to identify specific features that might be useful in the early recognition of HIV infection in MM patients.

\section{Methods}

A retrospective descriptive study was performed to investigate the demographic and clinical profile of HIV-positive MM patients at first presentation at Universitas Academic Hospital Complex in Bloemfontein, SA, a tertiary referral centre. This retrospective cohort study compared HIV-positive patients diagnosed with MM with HIV-negative MM patients. All patients diagnosed with MM during the period 1 January 2004 - 31 December 2011 with an HIV test result available were included in this study. Diagnosis was based on the then current diagnostic criteria of the International Myeloma Working Group of 2003 and clinical opinion of the haemato-oncologist, and may not meet the diagnostic criteria currently used. ${ }^{[22]}$ All plasmacytomas were histologically confirmed. The stage of disease was based on the International Staging System (ISS), which relies on serum albumin and $\beta 2$-microglobulin (B2M) levels. ${ }^{[23]}$

\section{Statistical analysis}

Data were analysed by the Department of Biostatistics at the University of the Free State, Bloemfontein, using the SAS 9.3 programme (SAS Institute, USA) for the frequency procedure, and Student's $t$-test and the $\chi^{2}$ test (with Fisher's exact test) where applicable. For non-parametric data, differences were tested by computing the median difference scores as proposed by Campbell and Gardner. ${ }^{[24]}$

\section{Ethical approval}

Ethical approval to conduct the study was obtained from the Ethics Committee of the Faculty of Health Sciences, University of the Free State (ref. no. ETOVS 187/2010).

\section{Results}

Of 146 patients diagnosed with MM during the study period, 89 (61.0\%) had an HIV test result available and were included in the study. Of these 89 patients, 16 (18.0\%) were HIV-positive. Characteristics of the HIV-positive cases are summarised in Table 1. The results of the comparison of HIV-positive and HIV-negative patients are summarised in Tables 2 and 3 .

\section{Demographics}

The median age of the HIV-positive patients was 51 years (range 36 - 68), which was significantly lower than that of the HIV-negative patients, with a median difference of 7 years $(95 \%$ CI 2 - 13). The male/female ratio in the HIV-negative patients was $1: 1$, compared with $3: 1$ in the HIV-positive group. In the HIV-negative group, 55 patients $(75.3 \%)$ were black, $10(13.7 \%)$ white and 7 (9.6\%) of mixed ethnicity, while 15 patients $(93.8 \%)$ in the HIV-positive group were black and $1(6.3 \%)$ was of mixed ethnicity.

\section{HIV status}

HIV was newly diagnosed during the work-up of MM in eight cases $(50.0 \%)$. In case 2 , the diagnosis of HIV was made 5 months after the initial presentation of MM. This patient was included on the basis of his low CD4 count and the high probability of his already having $\mathrm{HIV}$ at the time of being diagnosed with MM. For the other cases, the median time between the diagnosis of HIV and the presentation of MM was 6 months (mean 23, range 2 - 69). Only two patients (12.5\%) were on combined antiretroviral treatment (cART) at presentation with MM. The CD4 count was known for all the HIV-positive patients (median 212 cells $/ \mu \mathrm{L}$, range 65 - 625).

\section{MM staging}

Neither the median serum albumin levels nor B2M levels were significantly different between the two groups. The stage distribution based on the ISS was also similar (Table 4). In the HIV-negative group, immunoglobulin $\mathrm{G}(\mathrm{IgG})$ and IgA paraproteins and myeloma light-chain disease were mainly seen, while in the HIV-positive group only IgG paraproteins were found (Table 5). The percentage of patients with a newly diagnosed plasmacytoma at the time of presentation was not significantly different between the HIV-positive and HIV-negative groups.

\section{Bone marrow and radiographic findings}

No significant difference between the two groups was found for the median percentages of bone marrow plasma cells. Of the radiographic variables, the only difference was a significantly lower prevalence of osteolytic lesions in the HIV-positive group ( $73 \%$ v. 93\%; $p=0.03$ ), but no significant differences were seen for pathological fractures and vertebral collapse.

\section{Laboratory findings}

The median serum creatinine level was significantly lower in the HIV-positive patients than in those who were HIV-negative, with a median difference of $20 \mu \mathrm{mol} / \mathrm{L}$ (95\% CI 2 - 45). No significant difference was found for the percentages of patients presenting with Bence-Jones proteinuria. The median 24-hour measurement of protein in the urine was not significantly lower in HIV-positive patients, with a median difference of $0.43 \mathrm{~g} / 24 \mathrm{~h}(95 \% \mathrm{CI}-0.027$ 0.95). The serum Freelite kappa/lambda ratio was abnormal in $91 \%$ of HIV-negative and $69 \%$ of HIV-positive patients $(p=0.08)$.

The median platelet count was not significantly lower in the HIV-positive patients, with a median difference of $54 \times 10^{9} / \mathrm{L}(95 \%$ CI -2 - 117). In the HIV-negative group, $1 \%$ of the patients were severely thrombocytopenic $\left(<50 \times 10^{9} / \mathrm{L}\right)$, compared with $13 \%$ in the HIV-positive group. The lymphocyte count was only slightly lower in the HIV-positive patients, with a median difference of $0.21 \times 10^{9} / \mathrm{L}$ (95\% CI $-0.13-0.62)$. The neutrophil count was significantly lower in the HIV-positive patients, with a median difference of $1.13 \times 10^{9} / \mathrm{L}$ (95\% CI 0.16 - 2.4). There was a higher proportion of patients with a low neutrophil count $\left(<2 \times 10^{9} / \mathrm{L}\right)$ in the HIV-positive group than among those who were HIV-negative (31\% v. $11 \%)$.

\section{Discussion}

Although only two of the HIV-positive patients were on cART therapy at the time of diagnosis of MM, this group presented with comparable ISS stage of disease, pathological fractures, bone marrow 


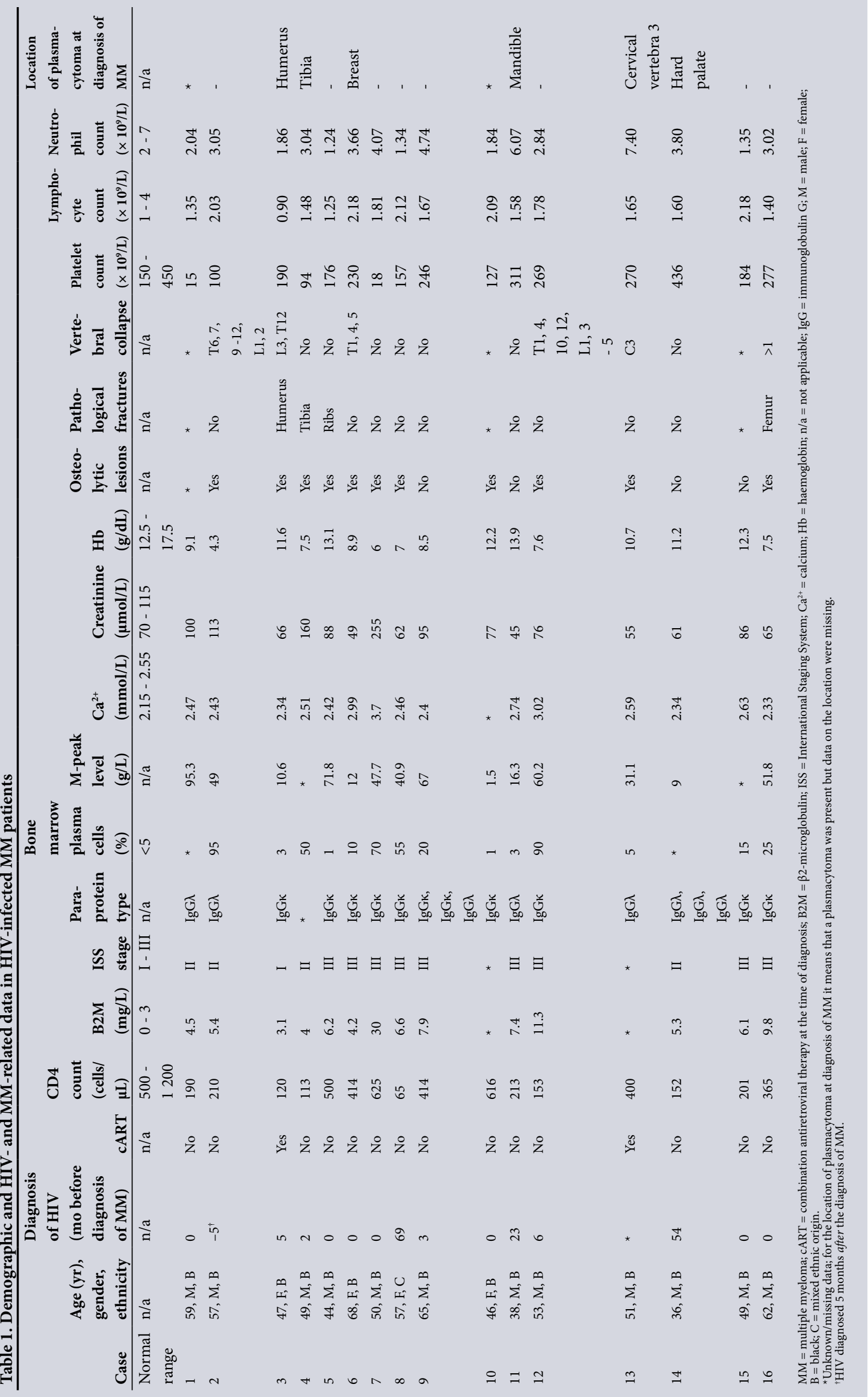


Table 2. Comparison of age and laboratory values in HIV-positive and HIV-negative MM patients

\begin{tabular}{|c|c|c|c|c|c|c|c|c|c|c|}
\hline \multirow[b]{2}{*}{ Variable } & \multicolumn{3}{|c|}{ HIV-negative $(N=73)$} & \multicolumn{3}{|c|}{ HIV-positive $(N=16)$} & \multicolumn{4}{|c|}{ Results } \\
\hline & $\begin{array}{l}\text { Patients } \\
\text { with } \\
\text { data, } n\end{array}$ & Median & Range & $\begin{array}{l}\text { Patients } \\
\text { with } \\
\text { data, } n\end{array}$ & Median & Range & $\begin{array}{l}\text { Median } \\
\text { difference }\end{array}$ & $\begin{array}{l}\text { Lower } \\
\text { CI }\end{array}$ & $\begin{array}{l}\text { Upper } \\
\text { CI }\end{array}$ & Significant \\
\hline Age $(y r)$ & 73 & 59 & $38-79$ & 16 & 50.5 & $36-68$ & 7 & 2 & 13 & Yes \\
\hline Serum creatinine $(\mu \mathrm{mol} / \mathrm{L})$ & 73 & 91 & $40-1666$ & 16 & 76.5 & $45-225$ & 20 & 2 & 45 & Yes \\
\hline Proteinuria (g/24 h) & 47 & 1.08 & $0.04-11.2$ & 13 & 0.59 & $1.10-2.21$ & 0.43 & -0.03 & 0.95 & No \\
\hline Haemoglobin (g/dL) & 73 & 9.7 & $3.2-15.8$ & 16 & 9 & $4.3-13.9$ & 0.3 & -1.3 & 1.9 & No \\
\hline Platelet count $\left(\times 10^{9} / \mathrm{L}\right)$ & 73 & 247 & $49-741$ & 16 & 187 & $15-436$ & 54 & -2 & 117 & No \\
\hline Lymphocyte count $\left(\times 10^{9} / \mathrm{L}\right)$ & 69 & 2 & $0.5-4.4$ & 16 & 1.7 & $0.9-2.2$ & 0.21 & -0.13 & 0.62 & No \\
\hline Neutrophil count $\left(\times 10^{9} / \mathrm{L}\right)$ & 70 & 4.2 & $1.1-12.2$ & 16 & 3 & $1.2-7.4$ & 1.13 & 0.16 & 2.4 & Yes \\
\hline
\end{tabular}

Table 3. Comparison of plasmacytoma prevalence and bone involvement in HIV-positive and HIV-negative MM patients

\begin{tabular}{|c|c|c|c|c|c|c|}
\hline \multirow[b]{2}{*}{ Variable } & \multicolumn{2}{|c|}{$\begin{array}{c}\text { HIV-negative } \\
(N=73)\end{array}$} & \multicolumn{2}{|c|}{$\begin{array}{l}\text { HIV-positive } \\
(N=16)\end{array}$} & \multicolumn{2}{|c|}{ Results } \\
\hline & $\begin{array}{l}\text { Patients with } \\
\text { data, } n\end{array}$ & Yes, $n(\%)$ & $\begin{array}{l}\text { Patients with } \\
\text { data, } n\end{array}$ & Yes, $n(\%)$ & Difference, $\%$ & $p$-value \\
\hline Plasmacytoma at presentation & 66 & $17(25.8)$ & 12 & $6(50.0)$ & -24.2 & 0.16 \\
\hline History of bone pain & 70 & $63(90.0)$ & 11 & $11(100)$ & -10.0 & 0.59 \\
\hline Osteolytic lesions & 70 & $65(92.9)$ & 15 & $11(73.3)$ & 19.6 & 0.03 \\
\hline Pathological fracture & 66 & $18(27.3)$ & 13 & $4(30.8)$ & -3.5 & 0.75 \\
\hline Vertebral collapse & 64 & $28(43.8)$ & 13 & $6(46.2)$ & -2.4 & 1.00 \\
\hline
\end{tabular}

Table 4. Comparison of ISS staging of HIV-positive and HIV-negative MM patients

\begin{tabular}{lll}
\hline & $\begin{array}{l}\text { HIV-negative } \\
(\boldsymbol{N}=73), \boldsymbol{n}(\%)\end{array}$ & $\begin{array}{l}\text { HIV-positive } \\
(\boldsymbol{N}=\mathbf{1 6}), \boldsymbol{n}(\%)\end{array}$ \\
\hline ISS stage I & $4(5.5)$ & $1(6.3)$ \\
ISS stage II & $28(38.4)$ & $6(37.5)$ \\
ISS stage III & $42(57.5)$ & $9(56.3)$ \\
\multicolumn{2}{l}{ ISS = International Staging System; MM = multiple myeloma. }
\end{tabular}

Table 5. Immunoglobulin paraproteins found in HIVpositive and HIV-negative MM patients

\begin{tabular}{|c|c|c|}
\hline $\begin{array}{l}\text { Immunoglobulin } \\
\text { paraprotein }\end{array}$ & $\begin{array}{l}\text { HIV-negative } \\
(N=73), \\
n(\%)\end{array}$ & $\begin{array}{l}\text { HIV-positive } \\
(N=16), \\
n(\%)\end{array}$ \\
\hline $\mathrm{IgG \kappa}$ & $36(49.3)$ & $10(62.5)$ \\
\hline $\operatorname{IgG} \lambda$ & $16(21.9)$ & $6(37.5)$ \\
\hline $\operatorname{IgA\kappa }$ & $4(5.5)$ & - \\
\hline $\operatorname{Ig} A \lambda$ & $8(11.0)$ & - \\
\hline$\kappa$ light chain & $7(9.0)$ & - \\
\hline$\lambda$ light chain & $2(2.7)$ & - \\
\hline
\end{tabular}

plasmacytosis, plasmacytomas, haemoglobin concentrations and platelet and lymphocyte counts to their HIV-negative counterparts. The gender distribution in the two groups was also similar. In contrast, the HIV-positive patients differed significantly from those who were HIV-negative in presenting at a younger age and having fewer osteolytic lesions, lower neutrophil counts and lower serum creatinine levels. Other notable findings were the high rate of newly diagnosed HIV patients, and the relatively high CD4 counts, the lower prevalence of abnormal serum Freelite kappa/lambda ratios and the exclusiveness of the IgG paraproteins in the HIV-positive group.

A possible limitation in the method used for this study that should be taken into account when interpreting further results, is the inclusion of all patients diagnosed with MM based on the then current diagnostic criteria of the International Myeloma Working Group of 2003 and clinical opinion of the haemato-oncologist. ${ }^{[22]}$ During the time period of the study, diagnostic criteria for MM have changed multiple times, and according to the leading criteria stated by the International Myeloma Working Group, patients 11, 14 and 15 may not have suffered from MM at that particular time. ${ }^{[25]}$ A solitary plasmacytoma with minimal bone marrow involvement and asymptomatic MM cannot be ruled out in these patients. Because the same changes in diagnostic criteria have occurred in the HIV-negative group, trends in differences between both groups will remain valuable, and the researchers have decided to keep these patients included in the analysis.

\section{Demographics}

Although age was significantly lower in the HIV-positive group than in the HIV-negative group, it is not comparable to the median age of 37 years described in the largest review of case reports of plasma cell tumours in HIV-positive patients. ${ }^{[26]} \mathrm{Li}$ et al. ${ }^{[16]}$ found ages and age differences that are comparable to our study. In contrast, the age difference was not significant in this study, possibly owing to their small population size. ${ }^{[16]}$ Many cancers are diagnosed at a younger age in HIV-positive patients than among uninfected individuals. ${ }^{[27]}$ One explanation for the lower age in the HIV-positive group may be that HIV infection is more prevalent among younger adults than elderly patients.

The ethnic distribution in the HIV-negative group reflects the population of the region in which the study was performed, where 
$79.5 \%$ were black, $9 \%$ white and $9 \%$ of mixed ethnic origin. ${ }^{[28]}$ The high percentage of blacks and the absence of whites in the HIVpositive group reflects the distribution pattern of HIV in the region.

\section{HIV status}

Fifty percent of the HIV-positive patients in this study were newly diagnosed with HIV during their work-up for MM. This finding is consistent with other case reports and reviews, where HIV infection was newly discovered during the evaluation for MM, and where it was previously stated that MM should be considered as a presenting symptom of HIV infection. ${ }^{[12,13,29]}$ Only two patients in our study were on cART at presentation with MM, and six patients were known to be HIV-positive but were not on therapy. Five of these six patients had a CD4 count of $<350$ cells $/ \mu \mathrm{L}$, the current level for initiation of cART in SA. ${ }^{[30]}$ During the period of this study, however, the cut-off for the initiation of ART changed from $<200$ cells/ $\mu \mathrm{L}$ to the new count of 350 cells $/ \mu \mathrm{L}$, which may explain why so many of our HIV-positive patients were not on therapy at the time of diagnosis of MM. ${ }^{[30]}$

The HIV-positive patients in this study presented with relatively high CD4 counts, in contrast to patients with HIV-related nonHodgkin lymphomas, most of whom have more advanced HIV infection and a CD4 count $<100$ cells/ $\mu \mathrm{L} .{ }^{[31,32]}$ Our findings are in line with the even higher CD4 counts in the HIV-positive MM patients studied by Li et al. ${ }^{[16]}$ Konstantinopoulos et al. ${ }^{[33]}$ performed protein electrophoreses and measured quantitative immunoglobulin levels in samples from 320 consecutive HIV-positive patients. Younger age and higher CD4 cell counts were significantly associated with monoclonal or oligoclonal banding, suggesting that younger HIVpositive patients with a more robust immune system (reflected by a higher CD4 count), which in this case is stimulated by uncontrolled viraemia, are most likely to have an augmented B-cell response to HIV infection. One manifestation of this B-cell response is low-concentration monoclonal banding in $4.4 \%$ of the patients studied. ${ }^{[33]}$ Whether this low-concentration monoclonal banding is premalignant and will progress to a malignant plasma cell neoplasm, such as monoclonal gammopathy of undetermined significance in a normal population, is unclear.

\section{Multiple myeloma staging}

All the HIV-positive patients in this study presented with IgGk or $\operatorname{IgG} \lambda$ paraproteins, with a predominance of light chains of the $\kappa$ type ( $\kappa: \lambda$ ratio 1.8 ). Two patients (12.5\%) presented with three monoclonal protein peaks. No patient had MM with another immunoglobulin subtype, light-chain disease or non-secretory myeloma, which were also reported previously to be rare. In a study of 1027 almost exclusively white MM patients, only $52 \%$ of the serum monoclonal proteins were of the IgG type. ${ }^{[34]}$ Briault et al. ${ }^{[35]}$ investigated the classes, subclasses and light-chain types of 78 serum monoclonal immunoglobulins from adult patients affected with various forms of HIV infection, and found that $91 \%$ were of the IgG class and $9 \%$ IgM, with a predominance of light chains of the $\lambda$ type ( $\kappa: \lambda$ ratio 0.6). The subclass distribution of IgG was strikingly different from that observed in MM, with much less IgG1 and much more IgG3 and IgG4 ${ }^{[35]} \mathrm{Ng}$ et al. ${ }^{[8]}$ presented seven cases of HIV-associated

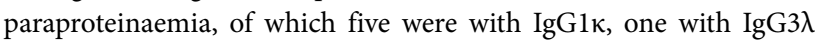
and one with $\operatorname{IgA} \lambda$. All $\operatorname{IgG} 1 \kappa$ paraproteins were reactive against HIV gag and pol antigens, while the other two types of paraproteins were not reactive to specific HIV antigens. ${ }^{[8]}$ Three other studies reported paraproteins that were specific for the HIV p24 and p31 antigens, and all paraproteins were of the IgGk type..$^{[9-11]}$

Lefrère et al. ${ }^{[36]}$ screened 341 asymptomatic HIV patients for over 6 years and found 11 cases of monoclonal gammopathy; again all

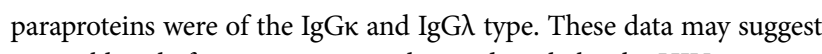
a possible role for antigenic stimulation directly by the HIV virion or other antigens in the pathogenesis of plasma-cell neoplasms in HIVassociated cases, and may indicate a causative role for HIV or an HIVassociated infection in MM. In contrast, in the study of Li et al. ${ }^{[16]}$ only seven out of $10 \mathrm{HIV}$-positive MM patients showed paraproteins of the IgG type and three patients were found to have an IgA paraprotein, $\kappa$-light chain disease or non-secretory myeloma. ${ }^{[16]}$ Previous studies have shown that patients with IgG-type MM have a better prognosis than those with IgA MM. Whether this is true in patients with HIVassociated MM will require evaluation in future research.

The HIV-negative group had a higher percentage of patients with an abnormal serum Freelite kappa/lambda ratio than the HIVpositive group. No studies could be found on this phenomenon in the HIV context, but it may be due to the effects of HIV infection on immunoglobulin levels. Hypergammaglobulinaemia is a feature of many chronic infections and is well recognised in HIV-positive individuals, in whom it often occurs in combination with a defective humoral immunity. ${ }^{[37,38]}$ Immunoglobulin levels become elevated from early stages of HIV-1 infection as a result of both specific and polyclonal activation of hyper-reactive naive B-cells. ${ }^{[39]}$ As polyclonal kappa and lambda light-chain production is not usually equal, an elevation in immunoglobulins may counterbalance the serum Freelite kappa/lambda ratio and lead to a false-normal value.

\section{Bone marrow and radiographic findings}

The significantly lower percentage of osteolytic lesions in the HIVpositive patients may have been due to their lower percentage of bone marrow plasma cells, as MM cells activate osteoclasts and influence the bone marrow environment, thereby promoting lytic bone lesions. ${ }^{[40]}$ In contrast, no differences were found in the prevalences of pathological fractures and vertebral collapses, which represent a huge cause of morbidity in MM patients. Whether the younger age in the HIV-positive group could possibly have been protective against the development of osteolytic lesions requires further investigation.

\section{Laboratory findings}

Although the glomerular filtration rate was not measured, the significantly lower serum creatinine levels and lower levels of proteinuria suggest relatively good renal function in the HIV-positive patients. This presumably lower prevalence of renal involvement in HIV-positive MM patients has not been reported previously. A reason for this phenomenon may be the younger age of the HIVpositive patients, and the fact that renal function declines with age and polypharmacy is usually more frequent among elderly patients.

The median numbers of platelets, lymphocytes and neutrophils were all lower in the HIV-positive patients than in those who were HIV-negative, but only the neutrophils were significantly lower. Neutropenia was found three times more frequently in the HIVpositive group. The incidence of neutropenia usually correlates directly with the degree of immunosuppression in HIV and varies from $5-10 \%$ in the early asymptomatic stages of infection to as high as $50-70 \%$ among patients with advanced disease. ${ }^{[41]}$ The cause of neutropenia is often multifactorial in HIV-positive patients, representing the combined effects of systemic infection, medications and HIV itself.

\section{Conclusion}

Even though studies have indicated an increased prevalence of MM in the HIV-positive population, very little was known about the demographic and clinical presentation of patients simultaneously suffering from both MM and HIV. This study represents the largest 
series of patients from a single centre and shows how similar the initial presentation of MM is in HIV-positive and HIV-negative patients. HIV-positive MM patients do present at a significantly lower age and with fewer osteolytic lesions, lower neutrophil counts, less renal impairment and fewer cases with abnormal Freelite kappa/ lambda ratios, and all M-proteins were of the IgG subtype. Except for the lower age, none of these findings are really specific enough to enable early recognition of these patients. Half of our patients were diagnosed with HIV during the work-up of MM, showing that MM could be seen as a presenting symptom of HIV, and as only $61 \%$ of the patients diagnosed with MM in our period of study had an HIV test result available, it is not unlikely that some HIV infections were missed. Especially since recent publications are showing trends of better overall and progression-free survival of HIV-positive MM patients compared with their HIV-negative counterparts, delayed or overlooked diagnosis of HIV would be a missed opportunity for early initiation of both antiretroviral therapy and treatment of the myeloma. We suggest that HIV infection should be tested for routinely in younger MM patients, especially in areas with a high prevalence of HIV. Because of the high prevalence of HIV infection in SA, and its possible implications with regard to treatment, it could be suggested that HIV should be tested for routinely in all patients newly diagnosed with a malignancy. Prospective studies are required to evaluate and compare different treatment strategies and outcomes of HIV-positive individuals with myeloma compared with their HIVnegative counterparts. In addition, larger prospective multicentre studies are needed to confirm some of the trends that did not reach statistical significance in this study, and leading diagnostic criteria for the diagnosis of MM should be used.

Acknowledgements. The authors gratefully thank Dr Dalene van Jaarsveld, medical officer at the Division of Clinical Haematology in the Department of Internal Medicine at Universitas Academic Hospital, Bloemfontein, for providing a list of all patients investigated for B2M in the diagnostic haematology laboratory.

Author contributions. JJBdeG designed and performed the research, analysed and interpreted data, and wrote and approved the manuscript; MJW designed the research, analysed and interpreted data, and contributed to revision and approval of the manuscript; JER designed the research, performed statistical analysis, analysed and interpreted data, and contributed to revision and approval of the manuscript; MCS assisted with interpretation of data, and writing, final editing and approval of the manuscript; and VJL designed and performed the research, analysed and interpreted data, and contributed to revision and approval of the manuscript.

Funding. None.

Conflicts of interest. None.

1. Katzel JA, Hari P, Vesole DH. Multiple myeloma: Charging toward a bright future. CA Cancer J Clin 2007;57(5):301-318. https://doi.org/10.3322/CA.57.5.301

2. Dal Maso L, Franceschi S. Epidemiology of non-Hodgkin lymphomas and other haemolymphopoietic neoplasms in people with AIDS. Lancet Oncol 2003;4(2):110-119. https://doi.org/10.1016/S1470 2045(03)00983-5

3. Grulich AE, van Leeuwen MT, Falster MO, Vajdic CM. Incidence of cancers in people with HIV/AIDS compared with immunosuppressed transplant recipients: A meta-analysis. Lancet 2007;370(9581):59-67. https://doi.org/10.1016/S0140-6736(07)61050-2

4. Sitas F, Pacella-Norman R, Carrara H, et al. The spectrum of HIV-1 related cancers in South Africa. Int J Cancer 2000;88(3):489-492. https://doi.org/10.1002/1097-0215(20001101)88:3\%3C489::AIDIJC25\%3E3.0.CO;2-Q

5. Stein L, Urban MI, O'Connell D, et al. The spectrum of human immunodeficiency virus-associated cancers in a South African black population: Results from a case-control study, 1995 - 2004. Int J Cancer 2008;122(10):2260-2265. https://doi.org/10.1002/ijc.23391

6. Coker WJ, Jeter A, Schade H, Kang Y. Plasma cell disorders in HIV-infected patients: Epidemiology and 6. Coker WJ, Jeter A, Schade H, Kang Y. Plasma cell disorders in HIV-infected patients: Epidem
molecular mechanisms. Biomark Res 2013;1(1):8-19. https://doi.org/10.1186/2050-7771-1-8

7. Pelicci PG, Knowles DM 2nd, Arlin ZA, et al. Multiple monoclonal B cell expansions and c-myc oncogene rearrangements in acquired immune deficiency syndrome-related lymphoproliferative disorders:
Implications for lymphomagenesis. J Exp Med 1986;164(6):2049-2060. https://doi.org/10.1084/ jem.164.6.2049

8. Ng VL, Chen KH, Hwang KM, Khayam-Bashi H, McGrath MS. The clinical significance of human immunodeficiency virus type 1-associated paraproteins. Blood 1989;74(4):2471-2475. http://scholar. google.co.za/scholar_url?url=https./www researchgate net/profie/Valerie Ng/publication/20352620 google.co.za/scholar_url?url=https://www.researchgate.net/profile/Valerie_Ng2/publication/20352620_ The_clinical_significance_of_human_immunodeficiency_virus_type_1-associated_paraproteins/

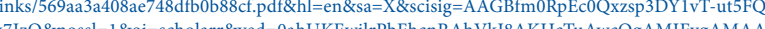
X7JzQ\&nossl=1\&oi=scholarr\&ved $=0$ ahUKEwjlrPbFhcnRAhVkJ8AKHcTuAwcQgAMIFygAMAA
(accessed 17 January 2017). (accessed 17 January 2017)

Piras MA, Salis T, Naitana AV, Spanu L, Aceti A. HIV infection and neoplasia. Lancet 1996;348(9037):13161317. https://doi.org/10.1016/S0140-6736(05)65801-1

10. Konrad RJ, Kricka LJ, Goodman DB, Goldman J, Silberstein LE. Brief report: Myeloma-associated paraprotein directed against the HIV-1 24 antigen in an HIV-1-seropositive patient. N Engl J Med 1993;328(25):1817-1819. https://doi.org/10.1056/NEJM199306243282505

11. Jin DK, Nowakowski M, Kramer M, Essex DW. Hyperviscosity syndrome secondary to a myelomaassociated $\operatorname{IgG}(1)$ kappa paraprotein strongly reactive against the HIV-1 p24 gag antigen. Am J Hematol 2000;64(3):210-213. https://doi.org/10.1002/1096-8652(200007)64:3\%3C210::AID-AJH13\%3E3.3.CO;2-R

2. Yee TT, Murphy K, Johnson M, et al. Multiple myeloma and human immunodeficiency virus-1 (HIV-1) infection. Am J Hematol 2001;66(2):123-125. https://doi.org/10.1002/10968652(200102)66:2\%3C123::AID-AJH1028\%3E3.3.CO;2-G

13. Feller L, White J, Wood NH, Bouckaert M, Lemmer J, Raubenheimer EJ. Extramedullary myeloma in an HIV-seropositive subject: Literature review and report of an unusual case. Head Face Med 2009;5:4. https://doi.org/10.1186/1746-160X-5-4

14. Pulik M, Genet P, Jary L, Lionnet F, Jondeau K. Acute myeloid leukemias, multiple myelomas, and culik M, Genet P, Jary L, Lionnet F, Jondeau K. Acute myeloid leukemias, multiple myelomas, and
chronic leukemias in the setting of HIV infection. AIDS Patient Care STDS 2009;12(12):913-919. https:// doi.org/10.1089/apc.1998.12.913

15. Karnad AB, Martin AW, Koh HK, Brauer MJ, Novich M, Wright J. Nonsecretory multiple myeloma in a 26-year-old man with acquired immunodeficiency syndrome, presenting with multiple extramedullary plasmacytomas and osteolytic bone disease. Am J Hematol 1989;32(4):305-310. https://doi.org/10.1002/ ajh. 2830320412

16. Li G, Lewis RD, Mishra N, Axiotis CA. A retrospective analysis of ten symptomatic multiple myeloma patients with HIV infection: A potential therapeutic effect of HAART in multiple myeloma. Leuk Res 2014;38(9):1079-1084. https://doi.org/10.1016/j.leukres.2014.07.001

17. Muzaffar J, Usmani S, Abdallah AO, Anaissie E, Cottler-Fox M, Restrepo A. High-dose chemotherapy and autologous stem cell transplantation for multiple myeloma in HIV-positive patients in the highly active antiretroviral therapy era: The myeloma institute of research and therapy experience. Clin Lymphoma Myeloma Leuk 2013;13(2):171-174. https://doi.org/10.1016/j.clml.2012.12.004

18. Agrawal S, Deshpande A. A unique presentation of multiple myeloma in an HIV patient. Indian J Med Res 2013;137(4):815-816. https://www.ncbi.nlm.nih.gov/pmc/articles/PMC3724269/ (accessed 17 January 2017).

19. Aboulafia DM. Thalidomide-based treatment for HIV-associated multiple myeloma: A case report. AIDS Read 2003;13(8):383-389. https://www.ncbi.nlm.nih.gov/pubmed/?term=Thalidomide-based+ treatment+foe+HIV-associated+multiple+myeloma\%3A+a+case+report (accessed 17 January 2017).

20. Kentos A, Vekemans M, van Vooren JP, et al. High-dose chemotherapy and autologous CD34-positive Kentos A, Vekemans M, van Vooren JP, et al. High-dose chemotherapy and autologous $\mathrm{CD} 34$-positive
blood stem cell transplantation for multiple myeloma in an HIV carrier. Bone Marrow Transplant blood stem cell transplantation for multiple myeloma in

21. Driessen C, Kraus M, Joerger M, et al. Treatment with the HIV protease inhibitor nelfinavir triggers the unfolded protein response and may overcome proteasome inhibitor resistance of multiple myelome in combination with bortezomib: A phase I trial (SAKK 65/08). Hematologica 2016;101(3):346-355. https:// doi.org/10.3324/haematol.2015.135780

22. International Myeloma Working Group. Criteria for the classification of monoclonal gammopathies, multiple myeloma and related disorders: A report of the International Myeloma Working Group. Br J Haematol 2003;121(5):749-757. https://doi.org/10.1046/j.1365-2141.2003.04355.x

23. Greipp PR, San Miguel J, Durie BG, et al. International staging system for multiple myeloma. J Clin Oncol 2005;23(15):3412-3420. https://doi.org/10.1200/JCO.2005.04.242

24. Campbell MJ, Gardner MJ. Statistics in medicine: calculating confidence intervals for some nonparametric analyses. Br Med J (Clin Res Ed) 1988;296(6634):1454-1456. https://doi.org/10.1136/ bmj.296.6634.1454

25. Rajkumar SV, Dimopoulos MA, Palumbo A, et al. International Myeloma Working Group updated criteria for the diagnosis of multiple myeloma. Lancet Oncol 2014;15(12):e538-e548. https://doi. org $/ 10.1016 /$ S1470-2045(14)70442-5

26. Salarieh A, Rao C, Gottesman SR, Alagha O, Todor R, Axiotis CA. Plasma cell tumours in HIV-positive patients: Report of a case and review of the literature. Leuk Lymphoma 2005;46(7):1067-1074. https://doi. $\mathrm{org} / 10.1080 / 10428190500054566$

27. Demopoulos BP, Vamvakas E, Ehrlich JE, Demopoulos R. Non-acquired immunodeficiency syndromedefining malignancies in patients infected with human immunodeficiency virus. Arch Pathol Lab Med 2003;127(5):589-592. http://www.archivesofpathology.org/doi/full/10.1043/0003-9985(2003)127\%3C05 89:NISMIP\%3E2.0.CO\%3B2 (accessed 17 January 2017).

28. Statistics South Africa. Mid-year population estimates 2011. http://www.statssa.gov.za/publications/ P0302/P03022011.pdf (accessed 17 January 2017).

29. Saif MW, Shannon K. Multiple myeloma and HIV infection: An association or a coincidence. J Appl Res 2005;5(2):318-324. http://jrnlappliedresearch.com/articles/Vol5Iss2/Saif\%20Myeloma.pdf (accessed 17 January 2017).

30. Meinties G, Maartens G, Boulle A, et al. Guidelines: Antiretroviral therapy in adults. S Afr J HIV Med 2012;13(3):114-133. https://doi.org/10.7196/sajhivmed.862

31. Koblin BA, Hessol NA, Zauber AG, et al. Increased incidence of cancer among homosexual men, New York City and San Francisco, 1978 - 1990. Am J Epidemiol 1996;144(10):916-923. https://doi.
. org/10.1093/oxfordjournals.aje.a008861

32. Levine AM, Seneviratne L, Espina BM, et al. Evolving characteristics of AIDS-related lymphoma. Blood 2000;96(13):4084-4090. http://www.bloodjournal.org/content/96/13/4084.long?sso-checked=true (accessed 17 January 2017)

33. Konstantinopoulos PA, Dezube BJ, Pantanowitz L, Horowitz GL, Bechwith BA. Protein electrophoresis and immunoglobin analysis in HIV-infected patients. Am J Clin Pathol 2007;128(4):596-603. https://doi. org/10.1309/QWTQFGA9FXN02YME

4. Kyle RA, Gertz MA, Witzig TE, et al. Review of 1027 patients with newly diagnosed multiple myeloma. Mayo Clin Proc 2003;78(1):21-33. https://doi.org/10.4065/78.1.21

35. Briault S, Courtois-Capella M, Duarte F, Aucouturier P, Preud'Homme JL. Isotypy of serum monoclonal immunoglobulins in human immunodeficiency virus-infected adults. Clin Exp Immunol 1988;74(2):182184. https://www.ncbi.nlm.nih.gov/pmc/articles/PMC1541791/ (accessed 17 January 2017).

36. Lefrère JJ, Debbia M, Lambin P. Prospective follow-up of monoclonal gammopathies in HIV-infected individuals. Br J Haematol 1993;84(1):151-155. https://doi.org/10.1111/j.1365-2141.1993.tb03038.x

37. Lane HC, Masur H, Edgar LC, Whalen G, Rook AH, Fauci AS. Abnormalities of B-cell activation and immunoregulation in patients with the acquired immunodeficiency syndrome. N Engl J Med 1983;309(8):453-458. https://doi.org/10.1056/NEJM198308253090803

38. Chong Y, Ikematsu H, Yamamoto $M$, et al. Effect of highly active antiretroviral therapy (HAART) on hypergammaglobulinemia in HIV infected patients [article in Japanese; English abstract]. Kansenshogaku Zasshi 2001;75(7):535-540. https://doi.org/10.11150/kansenshogakuzasshi1970.75.535 
39. Abelian A, Burling K, Easterbrook P, Winter G. Hypergammaglobulinemia and rate of HIV type 1 infection progression. AIDS Res Hum Retroviruses 2004;20(1):127-128. https://doi. (10.108980

40. Anderson KC, Carrasco RD. Pathogenesis of myeloma. Annu Rev Pathol 2011;6(1):249-274. https://doi. org/10.1146/annurev-pathol-011110-130249
41. Zon LI, Arkin C, Groopman JE. Haematologic manifestations of the human immune deficiency virus (HIV). Br J Haematol 1987;66(2):251-256. https://doi.org/10.1111/j.1365-2141.1987.tb01307.x

Accepted 2 May 2017. 